\title{
NV Energy Electricity Storage Valuation
}
JF Ellison
N Samaan
D Bhatnagar
C Jin

June 2013

Pacific Northwest

NATIONAL LABORATORY

Proudly Operated by Battelle Since 1965 


\title{
DISCLAIMER
}

This report was prepared as an account of work sponsored by an agency of the United States Government. Neither the United States Government nor any agency thereof, nor Battelle Memorial Institute, nor any of their employees, makes any warranty, express or implied, or assumes any legal liability or responsibility for the accuracy, completeness, or usefulness of any information, apparatus, product, or process diselosed, or represents that its use would not infringe privately owned rights. Reference herein to any specific commercial product, process, or service by trade name, trademark, manufacturer, or otherwise does not necessarily constitute or imply its endorsement, recommendation, or favoring by the United States Government or any agency thereof, or Battelle Memorial Institute. The views and opinions of authors expressed herein do not necessarily state or reflect those of the United States Government or any agency thereof.

\author{
PACIFIC NORTHWEST NATIONAL LABORATORY \\ operated by \\ BATTELLE \\ for the \\ UNITED STATES DEPARTMENT OF ENERGY \\ under Contract DE-AC05-76RL01830
}

Printed in the United States of America

Available to DOE and DOE contractors from the

Office of Scientific and Technical Information,

P.O. Box 62, Oak Ridge, TN 37831-0062;

ph: (865) 576-8401

fax: (865) 576-5728

email: reports@adonis.osti.gov

\author{
Available to the public from the National Technical Information Service, \\ U.S. Department of Commerce, 5285 Port Royal Rd., Springfield, VA 22161 \\ ph: (800) 553-6847 \\ fax: (703) 605-6900 \\ email: orders@ntis.fedworld.gov \\ online ordering: http://www.ntis.gov/ordering.htm
}

This document was printed on recycled paper. 


\title{
NV Energy Electricity Storage Valuation
}

\author{
JF Ellison ${ }^{1}$ \\ N Samaan ${ }^{2}$ \\ D Bhatnagar ${ }^{1}$ \\ C Jin ${ }^{2}$
}

June 2013

Prepared for

the U.S. Department of Energy

under Contract DE-AC05-76RL01830

Pacific Northwest National Laboratory Richland, Washington 99352

\footnotetext{
${ }^{1}$ Sandia National Laboratories

2 Pacific Northwest National Laboratory
} 



\begin{abstract}
This study examines how grid-level electricity storage may benefit the operations of NV Energy, and assesses whether those benefits are likely to justify the cost of the storage system. To determine the impact of grid-level storage, an hourly production cost model of the Nevada Balancing Authority ("BA") as projected for 2020 was created.

Storage was found to add value primarily through the provision of regulating reserve. Certain storage resources were found likely to be cost-effective even without considering their capacity value, as long as their effectiveness in providing regulating reserve was taken into account. Giving fast resources credit for their ability to provide regulating reserve is reasonable, given the adoption of FERC Order 755 ("Payfor-performance"). Using a traditional five-minute test to determine how much a resource can contribute to regulating reserve does not adequately value fast-ramping resources, as the regulating reserve these resources can provide is constrained by their installed capacity. To adequately value fastramping resources, NV Energy would need to adopt an alternate methodology for determining how much regulation is required that fully accounts for the speed of the contributing resources. Developing and modeling a new regulating reserve methodology for NV Energy was beyond the scope of this study. Assessing the incremental benefits and costs of distributed storage was also beyond the study scope.
\end{abstract}




\section{Executive Summary}

This study examines how grid-level electricity storage may benefit the operations of NV Energy in 2020, and assesses whether those benefits justify the cost of the storage system. The benefits examined are energy and reserve provision at the bulk grid level. In examining these benefits, the capacity value and electricity production cost savings were considered.

A nodal production cost model of the Nevada Balancing Authority ("BA") as projected for 2020 was created and used to estimate the production cost savings due to several hypothetical storage facilities. The Nevada grid is represented as a single BA, with the northern and southern grids connected by a single $500 \mathrm{kV}$ transmission line. Transmission lines and substations are represented in the model. Interties with neighboring BAs are represented, with intertie flows fixed at 2007 hourly levels. Data on NV Energy unit characteristics and load was provided by NV Energy. Data on non-NV Energy units, as well as on Nevada transmission lines and substations, is based on a Western Electricity Coordinating Council ("WECC”) dataset.

The storage scenarios examined in this study were selected to represent a range of possible sizes and grid services. Pumped storage hydro was chosen mainly to explore the value of time-of-day shifting. Lithium Ion batteries were chosen mainly to explore the value of spinning and regulation reserve. The storage scenarios were tested both in the northern and southern grids. Since a flexible generator can offer benefits to the grid similar to those offered by storage, the study team also specified two scenarios featuring new natural gas-fired reciprocating engine generators.

The study team drew the following conclusions:

- All storage scenarios examined enabled the grid to be operated at lower cost

- Storage was found to add value mainly by providing regulating and spinning reserve

- In the reference case, the Higgins Combined Cycle plant is frequently operated at mini- mum level to provide reserve

- When storage is introduced, least-cost dispatch favors using it for the provision of regulating and spinning reserve, thus reducing the need to use Higgins for this function

- With storage providing reserve, Higgins is dispatched less frequently, and dispatched at a higher level when needed (mainly for energy)

- Dispatching Higgins less means that more efficient plants can be dispatched more

- If regulating reserve from storage is valued the same as that from slower ramp rate resources, it appears that

- a reciprocating engine generator could provide additional capacity at a lower cost than a pumped hydro storage plant or large storage capacity battery system

- not taking into account its capacity value, a 25-MW/25-MWh battery storage facility would need to cost $\$ 650 / \mathrm{kW}$ or less in order to produce a positive NPV 
- However, if the fast, responsive regulating reserve provided by storage is considered to be more useful to the grid than that from slower ramp rate resources

- then a grid-level storage facility may have a positive NPV even at today's storage system capital costs (about $\$ 1100 / \mathrm{kW}$ for a Lithium Ion facility with one hour of storage)

Study model runs showed that scenario storage in the Nevada system mainly adds value by relieving the marginal combined cycle unit from providing spinning and regulating reserve. This means less generation from the marginal unit (since it is no longer operating at minimum load in order to provide reserve), more generation from the more efficient combined cycle units (in order to make up the generation shortfall), and more efficient generation from the marginal unit (as when it operates, it is operating at a higher level, and is thus more efficient).

In the model runs performed, the hypothetical storage units relieve the burden of providing spinning and regulating reserve from the Higgins Combined Cycle plant, which was the largest provider of both categories of these reserves in the reference run. Primarily, the Higgins plant was dispatched in the reference case not to provide energy, but to provide reserve. When relieved of reserve provision, the Higgins units are dispatched fewer hours, but at higher levels.

If additional peak production capacity is needed, it makes sense to compare the economics of a peaking plant with that of, say, a pumped storage hydro or a four-hour battery facility. Given the assumptions used for the discount rate, project capital cost, and natural gas prices, assuming the level of savings achieved in the study year are a good approximation of the savings that accrue each year in the future, and assuming that regulating reserve from storage is valued the same as that from a slower resource, it seems that a modern, efficient reciprocating engine power plant would be a more costeffective investment than would a storage facility.

While storage facilities with one hour of storage capacity are unlikely to significantly count towards additional peak generation capacity, in the study model runs they were more cost-effective at reducing production cost than storage with a larger energy capacity. This is because they reduced production cost almost as much as the larger energy capacity devices, at a much lower installed cost. Even so, the 25MW/25-MWh battery at Carson, under the assumptions used in this study, still yields an NPV of negative $\$ 11$ million. Reducing the capital cost of the battery storage system to $\$ 650 / \mathrm{kW}$ would provide for a NPV of zero.

Since the scenario storage facilities mainly added value by providing regulating reserve, storage valuations are sensitive to how regulating reserve is specified, and how much a megawatt of regu- lating reserve from a storage device counts towards fulfilling the regulating reserve requirement. A megawatt of regulating reserve from a fast-responding resource may be able to replace two to three megawatts of a slower-responding resource (Makarov, 2008). This effect was not taken into account in this study. If considered, a properly specified grid-level storage facility may have a positive NPV in Nevada even at today's storage system capital costs.

In this study, the ability of storage to provide energy and reserve at the bulk grid level was examined. At the bulk level, a storage facility could also be used to provide transmission capacity expansion deferral, reactive power supply, and black start service. If a storage project were to be realized as multiple distributed units, these units could provide substation capacity expansion deferral, feeder voltage control, and backup power. Distributed storage units could also collectively provide services to the bulk grid. The 
value of having storage provide services beyond reserve and time-of- day shifting at the bulk grid level was not assessed in this study, and was therefore not included in storage cost-benefit calculations. 


\section{Acknowledgment}

This research was sponsored by the Office of Energy Delivery and Energy Reliability's Energy Storage Program at the U.S. Department of Energy. The authors would like to thank Dr. Imre Gyuk and his colleagues at the Energy Storage Program at the U.S. Department of Energy for their funding and support of this project.

Tony Nguyen at PNNL assisted with the intertie flow data analysis and provided project input in the initial phase of the study. Michael Kintner-Meyer and Landis Kannberg at PNNL provided valuable technical feedback, as did Abraham Ellis and Ross Guttromson at Sandia. The Sandia and PNNL teams worked to benchmark the model against 2007 actual generator dispatch, and used the model for the study analysis. Meetings between the two teams were held on a weekly basis. This was truly a collaborative effort.

We would like to thank NV Energy personnel for their collaboration. We appreciate the input and assistance of Brenda Shank, Rich Salgo, Barbara Allen, Charlie Pottey, John Lescenski, and Susan Hill, as well as others we have neglected to name here. We also appreciate the efforts of Vladimir Chadliev, who was the NV Energy point of contact from project inception through November 2012. The willingness of NV Energy to collaborate improved both the quality of the data used and the authors' understanding of the NV Energy system. Any shortcomings in the report, however, are the responsibility of the authors alone. 


\section{Contents}

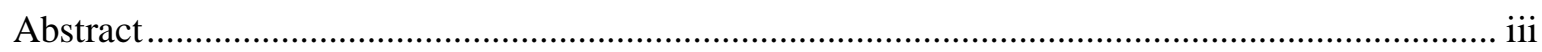

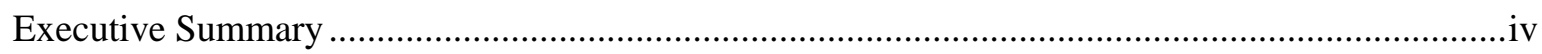

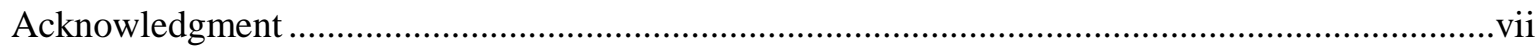

1.0 Background and Methodology …................................................................................. 1.1

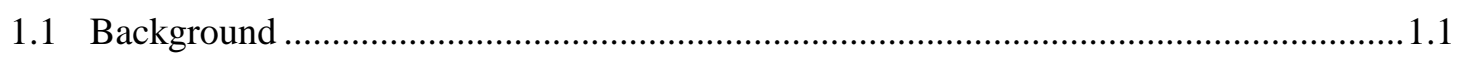

1.2 Study Objective and Scope .................................................................................... 1.1

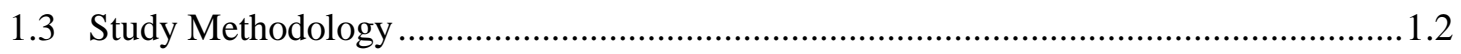

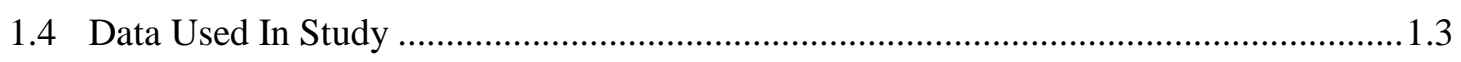

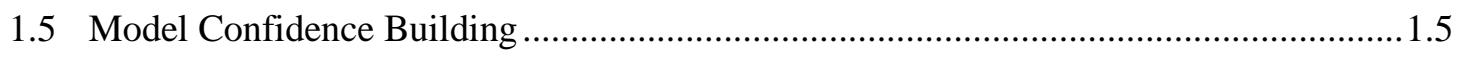

2.0 Study Scenarios and Reserve Requirements.................................................................2.1

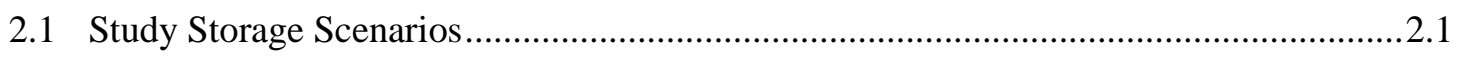

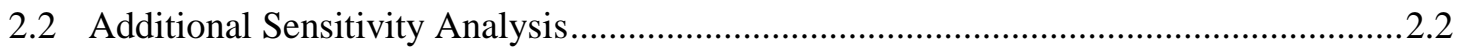

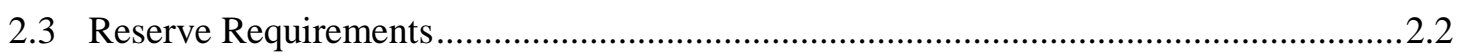

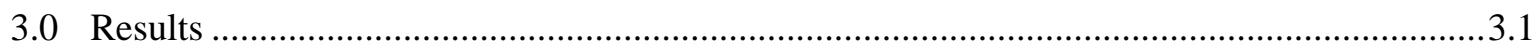

3.1 Pumped Storage Hydro Scenarios .............................................................................. 3.1

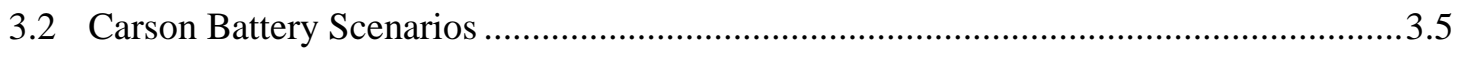

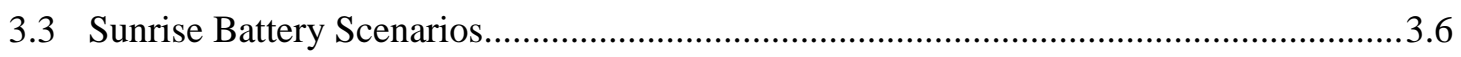

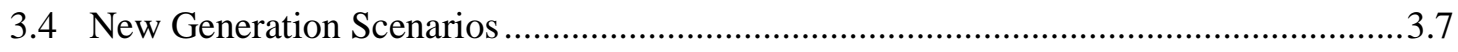

3.5 Additional Sensitivity Analysis Scenarios ................................................................. 3.7

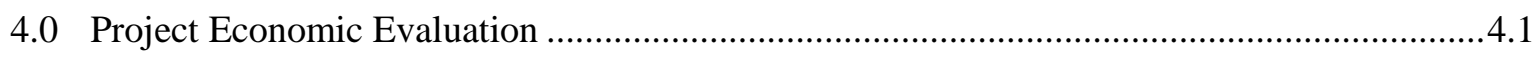

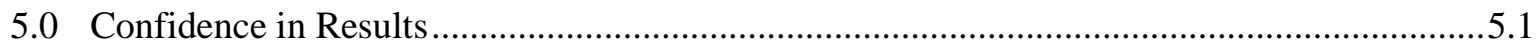

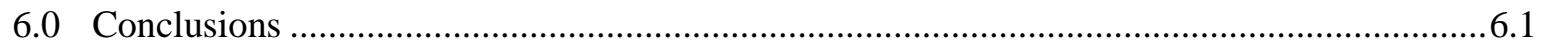

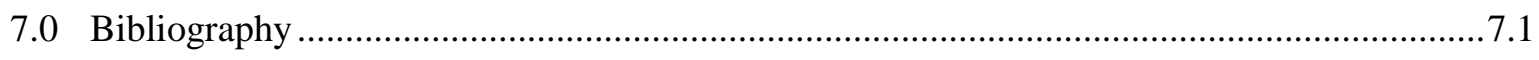

Appendix A Nevada BA Conventional Generation Assumed for 2020...........................................1

Appendix B Nevada BA Renewable Generation Assumed for 2020.......................................... B.1

Appendix C Choice of Nodes for Battery Storage ..................................................................... C.1 


\section{List of Figures}

Figure 1.1. Southern Nevada Simplified Interconnections ..................................................... 1.5

Figure 1.2. Northern Nevada Simplified Interconnections ....................................................... 1.5

Figure 3.1. Additional Storage System Sensitivity Results .............................................................

\section{List of Tables}

Table 1.1. Benchmark Run Results - Southern BA.................................................................

Table 1.2. 2007 Benchmark Run Results - Northern BA............................................................ 1.7

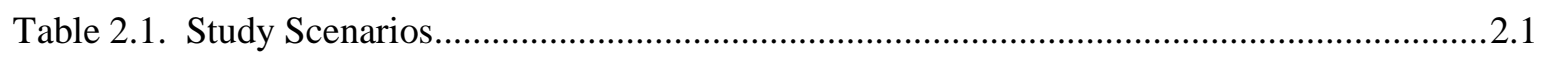

Table 2.2. Nevada Combined BA Operating Reserve Assumptions............................................2.3

Table 3.1. Summary Scenario Results ............................................................................................

Table 3.2. Load, Generation, and Pump Load by System.............................................................

Table 3.3. Pumped Storage Hydro Scenario Results .....................................................................

Table 3.4. Annual Reserve Supplied by Generator in Reference versus El Dorado Scenarios .......3.3

Table 3.5. Annual Generation in Reference versus El Dorado Scenarios.........................................

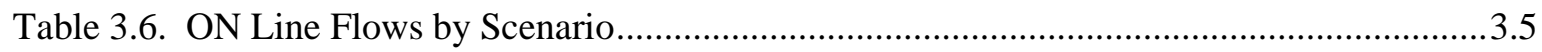

Table 3.7. Carson Lithium Ion Battery Scenario Results............................................................... 3.5

Table 3.8. Sunrise Lithium Ion Battery Scenario Results ............................................................6

Table 3.9. New Generation Plant Scenario Results .....................................................................

Table 4.1. Project Economic Evaluation........................................................................................ 4.1 


\subsection{Background and Methodology}

\subsection{Background}

With a service area of over 45,000 square miles, NV Energy provides electricity to most of Nevada. NV Energy is a vertically-integrated utility, and is the result of the merger of Nevada Power, Sierra Pacific Power, and Sierra Pacific Resources in July 1999 (NV Energy, 2013).

The northern and southern Nevada grids are not connected within Nevada, and are operated as two separate Balancing Authorities (“BAs”). However, a $500 \mathrm{kV}$ line linking these two grids is under construction, and should be completed in 2013. This line is called the One Nevada Transmission Line (the "ON Line"), and will extend roughly 230 miles from the Harry Allen substation (north of Las Vegas) to a new substation west of Ely, Nevada (Robinson Summit, hereafter referred to as "Robinson"). ${ }^{3}$ When this line is in operation, the combined grid will be operated as a single BA. This line is projected to have a capacity of about $760 \mathrm{MW}$. Though NV Energy is a minority owner in this line, it will make payments that give it the right to use the full capacity of the line.

There are two projects related to the ON Line that could be undertaken. One involves an additional $500 \mathrm{kV}$ link from the Robinson substation in Nevada to the Midpoint substation in Idaho, and a second involves a much shorter distance from the Harry Allen substation to the El Dorado substation. If these additional sections were built, together with the main ON Line segment they would form a 2000-MW transmission corridor into southern California. As of the writing of this report, it seems unlikely that these additional two segments will be built by 2020. Therefore, the model used for this analysis assumes only the Harry Allen - Robinson segment.

In 1997, the Nevada Legislature enacted a Renewable Portfolio Standard ("RPS”) into law. The Nevada Administrative Code specifies that the following resources are defined as renewable: geothermal, solar, wind, small hydro, biomass, and recovered energy from waste heat (NV Energy, 2012). The Nevada RPS specifies the percent of energy sold to Nevada retail customers that must be from renewable generation, which rises to 25 percent for $2025 .^{4}$

Nevada is fortunate to have significant renewable resources. Northern Nevada has high-quality geothermal and wind resources, and southern Nevada has a high-quality solar resource. Much of the renewable energy resources in Nevada are developed by independent developers, and purchased by NV Energy through power purchase contracts ("PPAs”). There is currently no grid-scale electricity storage in Nevada, though a couple of potential sites for a pumped storage hydro facility have been examined.

\subsection{Study Objective and Scope}

The objective of this study is to determine the value of grid-level electricity storage to the NV Energy system. Here, the value of storage is considered to be the value of the benefits the storage facility brings

\footnotetext{
${ }^{3}$ Source: NV Energy factsheet, https://www.nvenergy.com/company/projectsimages/ONLineTransmissionLineFactSheet.pdf, accessed 26 Juen 2013.

${ }^{4}$ Source: NRS 704.7801, http://www.leg.state.nv.us/Nrs/NRS-704.html\#NRS704Sec7801, accessed 27 June 2013.
} 
to the NV Energy system as a whole. (An independent developer would need to know what stream of payments a new storage facility might receive. This depends on the nature of the agreement with the utility, and is a question that we will not address here.)

This study focuses on quantifying the benefits of storage at the bulk grid level for energy and reserve provision. Whether there are likely to be any transmission bottlenecks that could be relieved by storage will also be addressed.

At the bulk level, a storage facility could also be used to provide transmission capacity expansion deferral, reactive power supply, and black start service. If a storage project were to be realized as multiple distributed units, these units could provide substation capacity expansion deferral, feeder voltage control, and backup power. Distributed storage units could also collectively provide services to the bulk grid. The value of having storage provide services beyond spinning and regulation reserve and time-of-day shifting at the bulk grid level was not assessed in this study, and was therefore not included in storage cost-benefit calculations.

The year 2020 was chosen for the study. A significant amount of renewable energy must be on the grid by this time (for 2020, the RPS is 22 percent), and there is a high degree of certainty as to the generation unit fleet composition for NV Energy. The 2020 production cost case assumed an installed capacity of $400 \mathrm{MW}$ of wind, $170 \mathrm{MW}$ of solar photovoltaic, and $185 \mathrm{MW}$ of solar thermal.

\subsection{Study Methodology}

For this analysis, we chose to examine the north and south Nevada grid as it is anticipated for 2020 . While the northern and southern systems are operated as two separate Balancing Authorities ("BAs") now, in the study year 2020 it is anticipated that they will be operating as a single BA. Throughout this report, we will refer to this combined system as the Nevada BA, or Nevada grid.

A nodal production cost model was built that represents the Nevada BA as anticipated in 2020. The model performs unit commitment, economic dispatch, and reserve procurement for the Nevada BA for 2020. The time resolution of the model is one hour, which means that the load and variable generation are specified on an hourly basis, and unit commitment, dispatch, and reserve procurement are calculated on an hourly basis.

Several possible storage and new generation facilities were specified. A model reference case (no additional storage) was run, and this was compared against runs with different scenario storage devices. The annual cost of producing power and supplying reserve in the runs with additional storage was compared to the reference run annual cost. Any savings in annual production cost in the runs with additional storage must have been due to the services supplied by the storage device. This annual cost savings, therefore, is considered to be the annual benefit supplied by the storage device.

How storage will be used is determined by the production cost model optimization process. Storage can be used to provide reserve, energy, or a combination of the two. The optimization process calculates the combination of reserve and energy that results in the greatest savings for the system. If the differential between marginal production cost at low and high load is greater than the round- trip efficiency loss of the storage unit, then the storage unit may be dispatched to charge at low load and generate at high load. If providing regulating and/or spinning reserve provides a greater benefit to the system than does time-of- 
day shifting, then the model may choose to use the storage for reserve provision. It is important to note that this type of storage optimization reflects the value of storage to the system as a whole, and is how a utility owning the storage device would probably want to use it. If the storage unit is developed by a third party, then it will be operated in order to capture value for the owner, which may result in dispatch that differs from that projected here.

The optimization in this model is performed over a 24-hour period, with an additional 24-hour period look-ahead. This means that the model can base decisions on unit commitment, dispatch, and storage use on perfect knowledge over a 48-hour period. This gives the model more precise information than would be available to a system operator in reality. At the same time, it gives the model no information whatsoever about periods beyond the 48-hour horizon. An actual ISO would at least have a good projection of load several days into the future. Since considering load and variable generation forecast error was not part of the scope of this study, the study team felt that a 48-hour optimization horizon was a good compromise between having too much or too little information.

Whether the new storage facility can be considered justifiable on a project economics basis depends on whether the Nevada grid needs additional capacity, and if so, whether storage or some other resource is the most cost-effective way of adding that capacity. Assuming additional capacity is needed, then the project chosen should be the one with the highest net present value ("NPV"). To calculate this NPV, it is necessary to estimate the capital cost of the project, the annual benefits supplied by the storage facility, and the discount rate applied to future cash flows. In this NPV calculation, the annual benefits, as calculated by the production cost model for 2020, are projected to continue for the life of the project.

The study team chose to examine the entire Nevada BA, as opposed to only the generation units belonging to NV Energy, or only those loads served by NV Energy. The reason for this is that the transmission grid within Nevada is represented in the production cost model. If non-NV Energy generation units and loads are not considered, then a portion of the demand for transmission will not be accounted for. The transmission system would appear to be more lightly loaded than in reality.

The Western Interconnect outside of the Nevada BA is not represented in this study. We assume that the intertie power flows in the study year are the same as actual intertie power flows in 2007. There are several reasons why we believe using fixed 2007 intertie flows is justified. First, most transactions between Nevada and its neighboring BAs are based on contracts, not spot markets. The 2007 flows capture many of the flows that are based on long-term contracts, such as flows from Hoover Dam and from the Navajo power plant. Second, fixing external flows isolates the impact of the scenario storage facilities on the cost of generation within Nevada. If the case for storage is highly dependent on assumptions about sales to and purchases from external markets, any such project will be viewed as highly speculative.

\subsection{Data Used In Study}

Data on NV Energy thermal unit characteristics (such as heat rates) was provided from NV Energy, as was information on expected renewable and conventional generation fleet composition in 2020. Data on non-NVE generation units within the Nevada BA was taken from the Transmission Expansion Planning 
Policy Committee (“TEPPC”) 2020 dataset for the Western Interconnection. ${ }^{5}$ In addition, the Nevada BA transmission network topology, flow constraints, and connectivity of generation units to nodes in the network were also taken from the TEPPC 2020 dataset.

The load data used in this study was provided by NV Energy, and is from 2007 recorded data. That year, the southern Nevada BA load was 25,900 GWh, and northern Nevada BA load was 11,930 GWh. Since the study is for system year 2020, the study team multiplied the 2007 hourly load by a factor to yield the projected 2020 load. That factor was roughly a 5 percent increase for southern Nevada, and a 23 percent increase for northern Nevada. (The reason for the large increase in northern Nevada is that a number of new mining operations are expected to open).

Data for the solar generation plants was also based on 2007 weather data, and was generated by Sandia for the Nevada Solar Integration Study (Lu, 2011). The wind data was from 2010, and was supplied by NV Energy. While having 2007 wind data would be preferable, this data was not available. Given the variability of wind from year to year, the study team felt that the impact of not having timecoincident wind data would be small.

A list of the generation units assumed to exist in the 2020 Nevada Balancing Authority is attached as Appendix A.

A significant amount of effort was expended to determine the most important external transmission links between NV Energy (both the southern and northern grids) with the rest of the Western Interconnect. This was done using load flow models in the GE PSLF (Positive Sequence Load Flow) software package. Figure 1.1 and Figure 1.2 show the equivalent links where actual import/export data were used as positive and negative generation injection.

\footnotetext{
${ }^{5}$ For additional information on the TEPPC 2020 dataset, please see the Assumptions Matrix for the 2020 TEPPC Dataset (TEPPC, 2010).
} 


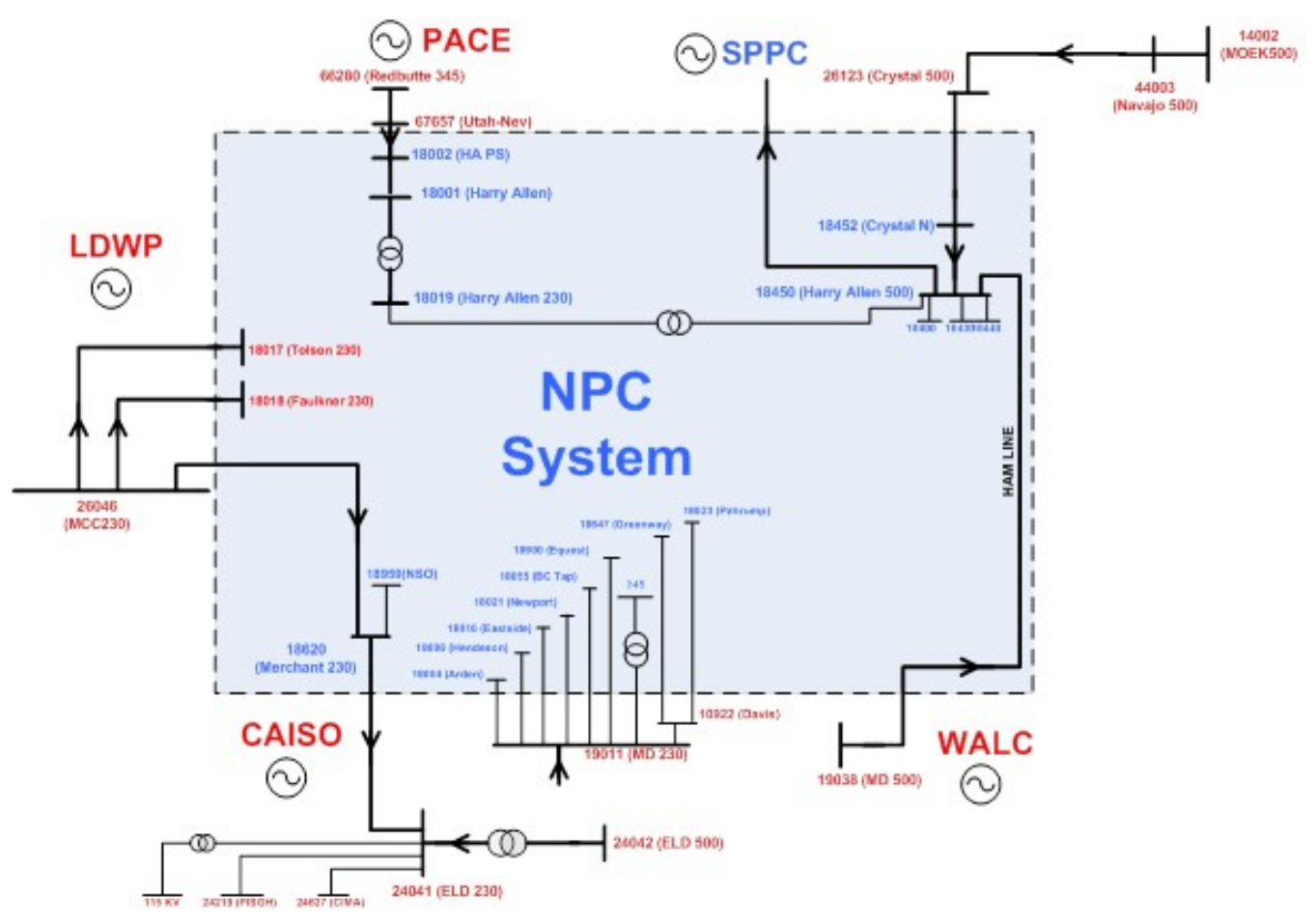

Figure 1.1. Southern Nevada Simplified Interconnections

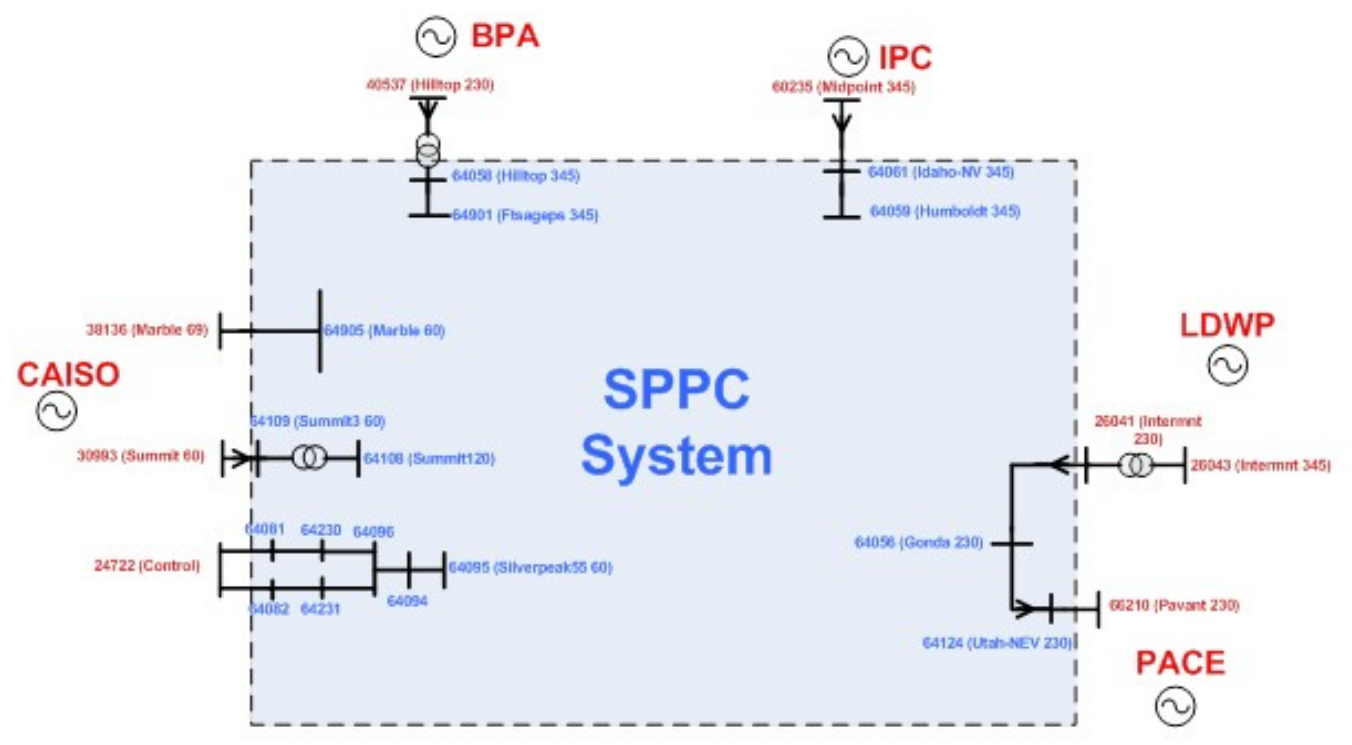

Figure 1.2. Northern Nevada Simplified Interconnections

\subsection{Model Confidence Building}

The study team set out to build confidence in the production cost model built for this study by benchmarking it against actual operational results. Since 2007 load, solar, and intertie flow data were available, the team chose to benchmark the model against 2007 operational results. We removed those units (both conventional and renewable) that were not available in 2007, fixed the intertie flows to their actual 2007 values, and ran the model. 
The results of the 2007 benchmark run were then compared against actual operational results. We found that one of the generators in particular, the W.M. Higgins combined cycle plant, was dispatched by the model to dispatch more than twice the amount it actually generated in 2007 . We decided to model the combined cycle block as its three separate constituent units - two gas turbines and one steam generator. This time, the model dispatched the Higgins units about 20 percent under 2007 actual generation. Evidently, the way we had first represented Higgins made it appear to the model to be more efficient than it is in reality. The study team also noticed that the two Clark Complex combined cycle units were dispatched less in the model than they were in reality. Converting these to their constituent units (three units each) did not increase their dispatch.

Table 1.1 shows the results of the benchmark runs for the southern grid, and Table 1.2 shows the results of the runs for the northern grid.

Table 1.1. Benchmark Run Results - Southern BA

\begin{tabular}{lcc}
\hline $\begin{array}{c}\text { Generator Name } \\
\text { (numbers in GWh) }\end{array}$ & $\begin{array}{c}\text { Modeled } \\
\text { Generation }\end{array}$ & $\begin{array}{c}\text { Actual } \\
\text { Generation }\end{array}$ \\
\hline Clark CC1 & 85 & 667 \\
Clark CC2 & 90 & 675 \\
Clark GT4 & 0.4 & 79 \\
Reid Gardner 1 & 727 & 584 \\
Reid Gardner 2 & 726 & 775 \\
Reid Gardner 3 & 724 & 691 \\
Reid Gardner 4 & 1,906 & 1,930 \\
Lenzie CC1 & 4,184 & 3,470 \\
Lenzie CC2 & 3,731 & 3,470 \\
Harry Allen GT3 & 0.3 & 27 \\
Harry Allen GT4 & 2 & 39 \\
Silverhawk CC1 & 2,854 & 2,889 \\
WM Higgins CC1 & 1,137 & 1,435 \\
Total Southern BA & 16,166 & 16,731 \\
\hline
\end{tabular}

As can be seen, most of the units were dispatched at levels reasonably close to 2007 output. Since the model did not take into account actual 2007 scheduled or forced outages, one would not expect the model output to precisely mimic reality. Fine-tuning the model to exactly replicate 2007 operations was not our goal, since we are ultimately interested in how the system performs in 2020.

Table 1.2 shows a modeled NV Energy northern grid generation that is $10 \%$ higher than in historical operations, which is a larger discrepancy than the modeled NV Energy southern grid generation (as shown in Table 1.1) that is 3\% lower than in historical operations. It is important to note that in these runs, non-NV Energy generation was taken into account. Non-NV Energy generation includes generators that NV Energy did not own but had a power purchase agreement (PPA) with (such as the geothermal plants), as well as third-party generation that NV Energy did not have a PPA with. The data for the nonNV Energy plant characteristics was not provided by NV Energy, but was based on 2020 system data from the Western Electricity Coordinating Council (“WECC”). 
Table 1.2. 2007 Benchmark Run Results - Northern BA

\begin{tabular}{lcc}
\hline \multicolumn{1}{c}{$\begin{array}{c}\text { Generator Name } \\
\text { (numbers in GWh) }\end{array}$} & $\begin{array}{c}\text { Modeled } \\
\text { Generation }\end{array}$ & $\begin{array}{c}\text { Actual } \\
\text { Generation }\end{array}$ \\
\hline Fort Churchill 1 & 526 & 502 \\
Fort Churchill 2 & 422 & 431 \\
Clark Mountain 3 & 98 & 43 \\
Clark Mountain 4 & 44 & 34 \\
Tracy 4 and 5 (Pin on) & 745 & 654 \\
Tracy ST1 & 18 & 82 \\
Tracy ST2 & 113 & 191 \\
Tracy ST3 & 438 & 358 \\
Valmy 1 & 1,839 & 1,722 \\
Valmy 2 & 2,021 & 1,666 \\
Total Northern BA & 6,264 & 5,683 \\
\hline
\end{tabular}

The WECC unit characteristics data for the northern grid may represent the non-NV Energy units as being less efficient than they are in reality, which would cause the model to dispatch NV Energy units more than they actually were. Alternatively, it could be that since the non-NV Energy units are not economically dispatched (instead, they are dispatched on the basis of bilateral contracts or ownership), they were operated more in reality than economic dispatch (which is what the production cost model does) would suggest.

Despite the higher level of NV Energy unit generation for the northern grid, the study team felt that the conventional NV Energy units were being dispatched in a way that was broadly consistent with actual 2007 operations. We were then ready to proceed with the storage valuation analysis. 


\subsection{Study Scenarios and Reserve Requirements}

\subsection{Study Storage Scenarios}

The storage scenarios examined in this study were selected to represent a range of possible sizes and grid services. Pumped storage hydro ("PSH") was chosen mainly to explore the value of time-of-day shifting, as it excels at storing large volumes of energy. Lithium Ion batteries were chosen mainly to explore the value of spinning and regulation reserve, as they can perform these functions with high efficiency and at a capital cost competitive with other battery types. ${ }^{6}$ Since a flexible generator can offer benefits to the grid similar to those offered by storage, the study team also specified two scenarios featuring new reciprocating engine generators (fueled by natural gas). Table 2.1 shows the scenarios examined.

Table 2.1. Study Scenarios

\begin{tabular}{lll}
\hline \multicolumn{1}{c}{ Technology } & \multicolumn{1}{c}{ Power/Storage Capacity } & \multicolumn{1}{c}{ Location } \\
\hline Pumped Storage Hydro & $300 \mathrm{MW} / 2400 \mathrm{MWh}$ & $\begin{array}{l}\text { El Dorado (southern grid) Robinson } \\
\text { (northern grid) Both of the above }\end{array}$ \\
& $300 \mathrm{MW} / 2400 \mathrm{MWh}$ & \\
$600 \mathrm{MW} / 4800 \mathrm{MWh}$ & \\
Lithium Ion Battery & $100 \mathrm{MW} / 400 \mathrm{MWh}$ & Carson (northern grid) Carson \\
& $100 \mathrm{MW} / 100 \mathrm{MWh}$ & Carson \\
& $50 \mathrm{MW} / 50 \mathrm{MWh}$ & Carson \\
& $25 \mathrm{MW} / 25 \mathrm{MWh}$ & \\
& $100 \mathrm{MW} / 400 \mathrm{MWh}$ & Sunrise (southern grid) Sunrise \\
Lithium Ion Battery & $100 \mathrm{MW} / 100 \mathrm{MWh}$ & Sunrise \\
& $50 \mathrm{MW} / 50 \mathrm{MWh}$ & Sunrise \\
& $25 \mathrm{MW} / 25 \mathrm{MWh}$ & \\
Reciprocating Engine Generator & $100 \mathrm{MW}$ & Carson \\
& $300 \mathrm{MW}$ & Carson \\
\hline
\end{tabular}

The pumped storage hydro plants are assumed to have a round-trip efficiency of $81 \%$, and the Lithium Ion batteries a round-trip efficiency of $90 \%$.

For the Pumped Storage Hydro, two locations are specified: El Dorado and Robinson. The 300 MW/2400 MWh system will be tested at Eldorado and Robinson separately, and another run will be done with both of them operational at the same time. These locations were chosen because developers have investigated sites near these substations, and have determined that the sites are suitable for pumped storage hydro facilities of roughly the size assumed here.

Choosing a location for the battery systems was more difficult, since they could be located anywhere on the system. Since there will be only one $500 \mathrm{kV}$ line connecting the northern and southern systems, the study team felt it would make sense to identify a node in each of these systems to locate the scenario

\footnotetext{
${ }^{6}$ To be clear, both the scenario PSH and lithium ion storage facilities were allowed to supply energy and reserve. The model used security-constrained unit commitment and economic dispatch to determine how the scenario storage devices should best be used to reduce the cost of producing power. The point here is that the large storage volume offered by PSH provides the system a great deal of time-of-day shifting flexibility, allowing the value of this service to be explored.
} 
battery storage facilities. The Sunrise node in the south and the Carson node in the north were chosen. Appendix $\mathrm{C}$ describes the process of choosing these two nodes.

All of the scenario storage systems tested were allowed to offer energy, spinning reserve, and regulation reserve. Even the battery systems with one hour of storage at full output were able to supply energy.

We did not include a flywheel storage device, other types of batteries, or a Compressed Air Energy Storage (CAES) facility as an explicit storage scenario. The reason for this is that we felt that the scenarios examined give a good picture of the system savings possible from a range of storage power and energy capacities. A one-hour lithium ion battery, for example, can provide regulating reserve at ramp rates high enough to make it comparable to a flywheel. There may be a trade-off between up-front capital cost and the life of the system (with the flywheel system most likely having the longer life). This type of analysis, however, can be done outside of the production cost model.

CAES is a type of storage system that competes with pumped storage hydro for storing large volumes of energy. While capital cost may potentially be lower for a CAES system (as compared with a pumped storage hydro system), round-trip efficiency is also likely to be lower. Moreover, CAES is site-specific, in that it requires an underground cavern suitable for holding compressed air. The study team is not aware of a possible CAES cavern in Nevada having been explored by developers in the way that pumped storage hydro sites have been explored.

\subsection{Additional Sensitivity Analysis}

In addition to the scenarios examined in Section 2.1, the study team performed additional sensitivity analysis runs. These runs considered a storage system with $81 \%$ round-trip efficiency, which is what was assumed for a pumped storage hydro plant. The runs examine storage systems with one, four, and eight hours of storage at several different power ratings: 100 MW, 300 MW, 500 MW, 1000 MW, and 2500 MW. These are modeled as being located at the Robinson substation in northern Nevada.

The purpose of these runs is to provide additional information on how storage is valued in the Nevada grid with respect to both power rating and energy storage capacity. As is the case with the other runs, the value of energy storage is considered to be the difference in annual operating cost to serve load between the reference system run and the run with the specified storage system in place.

\subsection{Reserve Requirements}

For this study, we assumed that the operating reserve requirements for the combined area are as indicated in Table 2.2. These requirements are the same as the operating reserve assumptions used by NV Energy (at the time of the writing of this report) in its integrated resource planning process. ${ }^{7}$

\footnotetext{
${ }^{7}$ Source: personal communication, Rich Salgo (NV Energy), February 3, 2012.
} 
Table 2.2. Nevada Combined BA Operating Reserve Assumptions

\begin{tabular}{lll}
\hline Reserve Category & Reserve Type & Reserve Quantity \\
\hline Quick Start Reserve & Non-synchronized & $1.5 \%$ of BA load + 1.5\% of NVE generation \\
Spinning Reserve & $\begin{array}{l}\text { Synchronized } \\
\text { Rynchronized } \\
\text { Regulating Reserve }\end{array}$ & $1.5 \%$ of BA load + 1.5\% of NVE generation \\
\hline
\end{tabular}

Quick Start Reserve is comprised of resources that are off-line, but that can be synchronized to the grid and provide a given level of output within ten minutes. Spinning Reserve is provided by resources that are synchronized to the grid, and have the capacity to increase production by the amount of spinning reserve offered. Regulating reserve is provided by units that are synchronized, have capacity to increase production, and are capable of receiving an Automatic Generator Control (“AGC”) signal that can set output target levels every four to six seconds.

Quick Start Reserve and Spinning Reserve are set aside mainly to give NV Energy the capability of making up lost power in the event of a contingency, such as a forced generator or transmission line outage. These two categories together are often termed Contingency Reserve. In the WECC, Contingency Reserve is typically 3\% of BA load plus 3\% of system generation, with at least half of this supplied by synchronized reserve. Regulating reserve is set aside to adjust generation to fast changes in load or variable energy production. Here, we assume that the total amount of regulating reserve set aside will be a constant $155 \mathrm{MW}$, which is comprised of the following: $35 \mathrm{MW}+4 \%$ of installed PV generation capacity $+25 \%$ of installed wind generation capacity. The $35 \mathrm{MW}$ is an estimate of the amount of regulating reserve needed to compensate for fast changes in load, and the other two components are an estimate of regulating reserve needed to compensate for fast changes in solar photovoltaic and wind output.

All three categories are mutually exclusive; in other words, the same megawatt of spare capacity cannot supply both spinning and regulating reserve - it must be allocated to one or the other. To allow the model the same flexibility as afforded by the WECC reliability rules, spinning reserve is allowed to increase above the 50\% fraction of Contingency Reserve, reducing the amount of Quick Start Reserve required, if providing the spinning reserve happens to be more economical than setting aside the quick start reserve.

We did not place restrictions in the model as to where the reserve was required. Thus, the model could supply reserve in the southern grid, northern grid, or a combination of the two as it found to be most cost-effective.

It is important to note that the study team did not perform an independent assessment of the level of reserve required by the NV Energy system. If it were possible to specify less reserve and still have adequate system security, then this would result in production cost savings. 


\subsection{Results}

Table 3.1 presents the production cost results of the scenarios examined. The numbers in the table are for the combined Nevada BA, and are in millions of US Dollars. The production cost model fixes hourly power imports from and exports to neighboring BAs to be the same as they were in 2007. The cost of power imported, and revenues from power exported, are not considered here. In addition, solar and wind generation is considered to be at zero cost, and the cost of geothermal generation is simply the variable operations and maintenance cost. As we are interested in the marginal cost of generation, ${ }^{8}$ capital costs are not considered for any generation resource.

Table 3.1. Summary Scenario Results

\begin{tabular}{lcccc}
\hline \multicolumn{1}{c}{$\begin{array}{c}\text { Scenario } \\
\text { (numbers in m USD) }\end{array}$} & $\begin{array}{c}\text { Generation } \\
\text { Cost }\end{array}$ & $\begin{array}{c}\text { Generator Start and } \\
\text { Shutdown Cost }\end{array}$ & $\begin{array}{c}\text { Total Generation } \\
\text { Cost }\end{array}$ & Savings \\
\hline Reference & 990.8 & 25.6 & $1,016.3$ & - \\
El Dorado 300 MW/2400 MWh PSH & 983.9 & 24.3 & $1,008.2$ & 8.1 \\
Robinson 300 MW/2400 MWh PSH & 984.6 & 24.6 & $1,009.1$ & 7.2 \\
El Dorado + Robinson PSH & 984.1 & 22.5 & $1,006.6$ & 9.8 \\
Carson 100 MW/400 MWh Battery & 987.3 & 25.6 & $1,012.9$ & 3.4 \\
Carson 100 MW/100 MWh Battery & 987.2 & 25.6 & $1,012.7$ & 3.6 \\
Carson 50 MW/50 MWh Battery & 989.1 & 25.1 & $1,014.2$ & 2.1 \\
Carson 25 MW/25 MWh Battery & 989.3 & 25.6 & $1,014.9$ & 1.5 \\
Sunrise 100 MW/400 MWh Battery & 986.6 & 24.6 & $1,011.2$ & 5.1 \\
Sunrise 100 MW/100 MWh Battery & 986.8 & 24.6 & $1,011.4$ & 4.9 \\
Sunrise 50 MW/50 MWh Battery & 988.7 & 25.4 & $1,014.1$ & 2.3 \\
Sunrise 25 MW/25 MWh Battery & 989.7 & 25.4 & $1,015.1$ & 1.2 \\
Carson 100 MW NewGen & 989.0 & 25.5 & $1,014.4$ & 1.9 \\
Carson 300 MW NewGen & 986.8 & 24.0 & $1,010.8$ & 5.6 \\
\hline
\end{tabular}

In order to better analyze the results, in this section these scenarios are grouped into the pumped storage hydro scenarios, Carson battery scenarios, Sunrise battery scenarios, and the new generation scenarios.

\subsection{Pumped Storage Hydro Scenarios}

There are primarily two sites where building a pumped storage hydro ("PSH”) facility would likely be feasible. These are near the El Dorado and Robinson substations, with El Dorado in the south and Robinson in the north of Nevada. The sites also constrain the feasible size of the pumped storage hydro facilities. Table 3.2 illustrates the load, generation, and pump load for the reference run and each of the three scenarios with pumped storage hydro facilities.

\footnotetext{
${ }^{8}$ The problem under consideration here is the efficient commitment and dispatch of generation units already in place. This problem does not require information on resource capital cost, which are sunk costs from the perspective of this analysis.
} 
Table 3.2. Load, Generation, and Pump Load by System

\begin{tabular}{|c|c|c|c|c|c|}
\hline \multirow[b]{2}{*}{$\begin{array}{c}\text { Region } \\
\text { (numbers in GWh) }\end{array}$} & \multirow[b]{2}{*}{ Attribute } & \multirow[b]{2}{*}{ Reference } & \multicolumn{3}{|c|}{ Difference from Reference } \\
\hline & & & $\begin{array}{l}\text { El Dorado } \\
\text { PSH }\end{array}$ & $\begin{array}{c}\text { Robinson } \\
\text { PSH }\end{array}$ & $\begin{array}{l}\text { El Dorado and } \\
\text { Robinson PSH }\end{array}$ \\
\hline \multirow{3}{*}{ Southern } & Load & 26,663 & +234 & - & +256 \\
\hline & Pump Load & - & +234 & - & +256 \\
\hline & Generation & 18,432 & +27 & -127 & +62 \\
\hline \multirow{3}{*}{ Northern } & Load & 14,171 & - & +235 & +227 \\
\hline & Pump Load & - & - & +235 & +227 \\
\hline & Generation & 14,361 & +207 & +362 & +421 \\
\hline \multirow{3}{*}{ Total } & Load & 40,834 & +234 & +235 & +483 \\
\hline & Pump Load & - & +234 & +235 & +483 \\
\hline & Generation & 32,793 & +234 & +235 & +483 \\
\hline
\end{tabular}

The load is higher when a pumped storage hydro facility is present, as the pump load becomes part of the total load. As evident in Table 3.2, the El Dorado PSH facility adds to the load in the south, and the Robinson PSH facility adds to the load in the north, because those are the areas the facilities are located in. We see that adjusted generation (defined here as generation minus the increase in load due to the PSH) increases in the north and drops in the south in the PSH scenarios as compared to the reference system.

Table 3.3 indicates the annual savings in 2020, as compared to the reference run, that would likely result from a facility at El Dorado, a facility at Robinson, and both facilities together.

Table 3.3. Pumped Storage Hydro Scenario Results

\begin{tabular}{lcccc}
\multicolumn{1}{c}{$\begin{array}{c}\text { Scenario } \\
\text { (numbers in m USD) }\end{array}$} & $\begin{array}{c}\text { Generation } \\
\text { Cost }\end{array}$ & $\begin{array}{c}\text { Generator Start and } \\
\text { Shutdown Cost }\end{array}$ & $\begin{array}{c}\text { Total Generation } \\
\text { Cost }\end{array}$ & Savings \\
\hline Reference & 990.8 & 25.6 & $1,016.3$ & - \\
El Dorado 300 MW/2400 MWh PSH & 983.9 & 24.3 & $1,008.2$ & 8.1 \\
Robinson 300 MW/2400 MWh PSH & 984.6 & 24.6 & $1,009.1$ & 7.2 \\
Both El Dorado and Robinson PSH & 984.1 & 22.5 & $1,006.6$ & 9.8
\end{tabular}

We notice that the PSH facilities at El Dorado and Robinson produce benefits of a similar size, while making both plants available yields only a small incremental benefit. How do these benefits arise? And are they mainly from the provision of reserve or energy? To answer this, it is helpful to examine the level of reserve provision and generation by the NV Energy conventional power plants in the reference case versus the El Dorado PSH scenario. The reserve provision comparison is given in Table 3.4, and the generation comparison is given in Table 3.5. In both tables, the numbers for the reference reserve represent the amount of reserve provision or amount of generation for the year (in GWh), whereas the numbers for the El Dorado scenario represent the difference from reserve provision or generation in the reference run. 
Table 3.4. Annual Reserve Supplied by Generator in Reference versus El Dorado Scenarios

\begin{tabular}{|c|c|c|c|c|c|c|c|}
\hline \multirow{3}{*}{$\begin{array}{l}\text { (in GWh) } \\
\text { Region }\end{array}$} & \multirow[b]{3}{*}{ Plant Name } & \multirow{2}{*}{\multicolumn{3}{|c|}{$\begin{array}{c}\text { Reference Reserve } \\
\text { Annual Provision }\end{array}$}} & \multirow{2}{*}{\multicolumn{3}{|c|}{$\begin{array}{c}\text { El Dorado Reserve } \\
\text { Annual Provision } \\
\text { (+/- reference) }\end{array}$}} \\
\hline & & & & & & & \\
\hline & & Spin & Reg & QS & Spin & Reg & QS \\
\hline \multirow{9}{*}{ Southern } & Harry Allen CC & 70 & 30 & 30 & +2 & +2 & -7 \\
\hline & Harry Allen GTs & 2 & 1 & 66 & -1 & -1 & -6 \\
\hline & Clark CCs & 49 & 116 & 181 & -36 & -80 & -12 \\
\hline & Clark GTs & 1 & 1 & 260 & -1 & - & -27 \\
\hline & Reid Gardner & - & 17 & 99 & +1 & -10 & -9 \\
\hline & Higgins CC & 630 & 848 & 77 & -479 & -756 & +79 \\
\hline & Lenzie CCs & 295 & 217 & 51 & +16 & -37 & +5 \\
\hline & Silverhawk CC & 44 & 14 & 118 & -9 & -1 & -10 \\
\hline & El Dorado PSH & - & - & - & +482 & +938 & +9 \\
\hline \multirow{6}{*}{ Northern } & Ft Churchill & 2 & 1 & 63 & -1 & -1 & -6 \\
\hline & Clark Mtn & - & - & 40 & - & - & -3 \\
\hline & Tracy $4 \& 5$ & 1 & 10 & 23 & +3 & -4 & -3 \\
\hline & Tracy Pwr Block & 5 & 96 & 39 & +25 & -47 & -4 \\
\hline & Tracy STs & 4 & 2 & 49 & +1 & -2 & -3 \\
\hline & Valmy & 1 & 4 & 9 & - & -2 & -1 \\
\hline TOTAL & & 1,104 & 1,357 & 1,104 & +4 & - & +4 \\
\hline
\end{tabular}

First, the El Dorado PSH facility provides much more in reserve than in generation. Annually, it provides about $480 \mathrm{GWh}$ in spinning reserve and $940 \mathrm{GWh}$ in regulation reserve, whereas it provides only about $190 \mathrm{GWh}$ in generation. (Here, generation is the amount provided in time-of- day shifting, which takes advantage of hourly differences in marginal generation costs).

Second, the Higgins Combined Cycle plant is dispatched much less in the El Dorado scenario. In the El Dorado case, it is dispatched about 540 GWh over the year, versus $1360 \mathrm{GWh}$ in the reference case. This shortfall of $820 \mathrm{GWh}$ is made up mainly by increased generation at the Lenzie Combined Cycle plant, the Harry Allen Combined Cycle plant, the Tracy Power Block, and Silverhawk Combined Cycle.

Putting this together, what we see is that the El Dorado PSH facility essentially relieves the burden of providing spinning and regulating reserve from the Higgins plant, which was the largest provider of both categories of these reserves in the reference run. The Higgins plant was dispatched in the reference case not primarily to provide energy, but to provide reserve. Higgins GT1 and GT2 were operated a combined 9,130 hours in the reference case, of which 5,860 hours (or $65 \%$ of the time) were at minimum load.

When relieved of this function, the Higgins units are dispatched in fewer hours, but at higher levels. In the El Dorado run, Higgins GT1 and GT2 were dispatched a combined 2,990 hours, of which 980 hours (or $33 \%$ of the time) were at minimum load. 
Table 3.5. Annual Generation in Reference versus El Dorado Scenarios

\begin{tabular}{clcc}
\hline $\begin{array}{c}\text { (in GWh) } \\
\text { Region }\end{array}$ & \multicolumn{1}{c}{ Plant Name } & $\begin{array}{c}\text { Reference Run } \\
\text { Generation }\end{array}$ & $\begin{array}{c}\text { El Dorado Scenario } \\
\text { Generation } \\
\text { (+/- reference) }\end{array}$ \\
\hline & Harry Allen CC & 2,812 & +258 \\
& Harry Allen GTs & 3 & -1 \\
& Clark CCs & 183 & -27 \\
& Clark GTs & 3 & -2 \\
Southern & Reid Gardner & 4,044 & +7 \\
& Higgins CC & 1,360 & -819 \\
& Lenzie CCs & 6,135 & +225 \\
& Silverhawk CC & 1,164 & +120 \\
& Non-System & 2,729 & +77 \\
& Ft Churchill & 5 & -3 \\
& Clark Mtn & 1 & +1 \\
& Tracy 4\&5 & 102 & -11 \\
Northern & Tracy Pwr Block & 3,988 & +208 \\
& Tracy STs & 24 & -4 \\
& Valmy & 3,889 & +12 \\
& Non-System & 6,351 & +5 \\
\hline \multirow{2}{*}{ TOTAL } & & 32,793 & +45 \\
\hline & & &
\end{tabular}

Therefore, we can say that the PSH facilities mainly add value by relieving the marginal combined cycle unit from providing spinning and regulating reserve. This means less generation from the marginal unit (since it is no longer operating at minimum load in order to provide reserve), more generation from the more efficient combined cycle units (in order to make up the generation short- fall), and more efficient generation from the marginal unit (as when it operates, it is operating at a higher level, and is thus more efficient).

This explanation helps us to understand why adding another 300-MW PSH facility adds little benefit to the system. Since a 300-MW PSH facility relieves the marginal combined cycle plant from most of the burden of providing reserve, and since this seems to be the primary way storage adds value to the system, adding another large block of storage does little to increase benefit to the system.

While understanding how PSH adds benefit to the system is most important, the fact that there is some difference between locating a PSH facility in the southern grid (at El Dorado) and in the northern grid (at Robinson) is worth exploring. It could be that locating storage in the south enables the ON Line (linking the southern and northern systems) to be used slightly more effectively in getting additional power from the Tracy Power Block to the southern grid.

Model runs show the ON Line to be at capacity (760 MW) $1.7 \%$ of the time in the reference run, $2.8 \%$ of the time with the pumped storage hydro facility at El Dorado, $2.4 \%$ of the time with the facility at Robinson, and $3.2 \%$ of the time with both facilities in place. Table 10 outlines the amount of power transfer on the ON Line in the reference run and the three pumped storage hydro scenarios. 
Table 3.6. ON Line Flows by Scenario

\begin{tabular}{lcccc}
\hline & & \multicolumn{3}{c}{ Difference from Reference } \\
\cline { 3 - 5 } Flow Direction (in & & & & El Dorado and \\
GWh) & Reference Case & El Dorado PSH & Robinson PSH & Robinson PSH \\
\hline Flows South & 2,777 & +197 & +126 & +197 \\
Flows North & 165 & -10 & -1 & +4 \\
Net Flows South & 2,612 & +207 & +127 & +194 \\
\hline
\end{tabular}

As compared with the reference run, annual net flows south increase by about $200 \mathrm{GWh}$ in the scenarios with El Dorado, and by about 125 GWh in the Robinson scenario. The $200 \mathrm{GWh}$ is roughly the amount of extra generation by the Tracy Power Block (an efficient plant in the northern grid) in all three PSH scenarios. (The reason for the lower net flows south in the Robinson PSH scenario is that locating the PSH in the northern grid places an additional load in that area, increasing the need for power in the north as compared with locating the PSH in the south at El Dorado) .

If the amount of generation at the efficient Tracy Power Block is roughly the same, what then accounts for the 0.8 million USD difference in cost between the El Dorado and Robinson PSH scenarios? Valmy, which is a low-cost coal plant in the northern grid, operates $11 \mathrm{GWh}$ more over the year in the El Dorado scenario. In addition, as compared to the Robinson scenario, the El Dorado scenario permits about $40 \mathrm{GWh}$ of generation to shift from the Silverhawk plant to the Lenzie plant (which is a more efficient plant). It is therefore a number of factors that lead to slightly better cost savings with the PSH located in the southern grid.

\subsection{Carson Battery Scenarios}

These scenarios examine the effects of a battery storage facility at the Carson substation in the northern grid. A 100-MW/4-hour system is examined, as are one-hour systems of 100MW, 50MW, and 25MW in capacity.

Table 3.7. Carson Lithium Ion Battery Scenario Results

\begin{tabular}{lccccc}
\hline $\begin{array}{c}\text { Scenario } \\
\text { (m USD, unless noted) }\end{array}$ & $\begin{array}{c}\text { Annual } \\
\text { Generation } \\
\text { Cost }\end{array}$ & $\begin{array}{c}\text { Generator Start and } \\
\text { Shutdown Cost }\end{array}$ & $\begin{array}{c}\text { Total } \\
\text { Generation } \\
\text { Cost }\end{array}$ & $\begin{array}{c}\text { Annual } \\
\text { Savings }\end{array}$ & $\begin{array}{c}\text { Savings/MW of } \\
\text { Storage Capacity } \\
\text { (USD) }\end{array}$ \\
\hline Reference & 990.8 & 25.6 & $1,016.3$ & - & - \\
Carson 100 MW/400 & 987.3 & 25.6 & $1,012.9$ & 3.4 & 34,000 \\
Carson 100 MW/100 & 987.2 & 25.6 & $1,012.7$ & 3.6 & 36,000 \\
Carson 50 MW/50 MWh & 989.1 & 25.1 & $1,014.2$ & 2.1 & 42,000 \\
Carson 25 MW/25 MWh & 989.3 & 25.6 & $1,014.9$ & 1.5 & 60,000 \\
\hline
\end{tabular}

As can be seen in Table 3.7, the results show declining benefits for additional amounts of capacity. For each megawatt of capacity, the annual savings is 60,000 USD for the 25-MW/25-MWh battery, 42,000 USD for the 50-MW/50-MWh battery, and 36,000 USD for the 100-MW/100-MWh battery. It is not surprising that storage offers diminishing returns to the grid. However, these results are useful, as they provide an idea of at what sizes and how fast the returns diminish. 
In addition, the results mirror those of the PSH runs, in that the model does find a use for additional energy storage volumes. The 100-MW/400-MWh battery system yields approximately the same level of benefit as does the 100-MW/100-MWh system. The model values the ability of the battery to provide reserve, and does not find benefit in using it for time-of-day shifting.

The slight drop in value with the 400-MWh battery system seems counterintuitive, as it seems that the model should not use it in ways that would cause its value to decrease below those provided by the 100MWh battery system of the same size. We believe that the slight decrease of 0.2 million USD with the 100-MW/400-MWh battery is likely an artifact of the model, and is related to the optimization horizon. (Since the model is optimizing over a single day plus a one-day look-ahead period, it could make a decision to use the four-hour storage capacity in a way that is beneficial in one two-day period, but where those benefits are outweighed by additional costs in the next two-day period.) In reality, a battery system with a larger energy storage capacity would not be deployed in a way that makes it less valuable to the grid than a battery with less energy storage capacity.

\subsection{Sunrise Battery Scenarios}

These scenarios examine the effects of a battery storage facility at the Sunrise substation in the southern grid. A 100-MW/4-hour system is examined, as are one-hour systems of $100 \mathrm{MW}, 50 \mathrm{MW}$, and 25 MW in capacity.

Table 3.8. Sunrise Lithium Ion Battery Scenario Results

\begin{tabular}{lccccc}
\hline $\begin{array}{c}\text { Scenario } \\
\text { (m USD, unless noted) }\end{array}$ & $\begin{array}{c}\text { Annual } \\
\text { Generation } \\
\text { Cost }\end{array}$ & $\begin{array}{c}\text { Generator Start and } \\
\text { Shutdown Cost }\end{array}$ & $\begin{array}{c}\text { Total } \\
\text { Generation } \\
\text { Cost }\end{array}$ & $\begin{array}{c}\text { Annual } \\
\text { Savings }\end{array}$ & $\begin{array}{c}\text { Savings/MW of } \\
\text { Storage Capacity } \\
\text { (USD) }\end{array}$ \\
\hline Reference & 990.8 & 25.6 & $1,016.3$ & - & - \\
Sunrise 100 MW/400 MWh & 986.6 & 24.6 & $1,011.2$ & 5.1 & 51,000 \\
Sunrise 100 MW/100 MWh & 986.8 & 24.6 & $1,011.4$ & 4.9 & 49,000 \\
Sunrise 50 MW/50 MWh & 988.7 & 25.4 & $1,014.1$ & 2.3 & 46,000 \\
Sunrise 25 MW/25 MWh & 989.7 & 25.4 & $1,015.1$ & 1.2 & 48,000 \\
\hline
\end{tabular}

Summary results of the Sunrise battery runs are shown in Table 3.8. Interestingly, the same clear pattern of diminishing returns does not emerge from these scenarios as from the Carson battery scenarios. For each megawatt of capacity, the annual savings is 48,000 USD for the 25-MW/25-MWh battery, 46,000 USD for the 50-MW/50-MWh battery, and 49,000 USD for the 100-MW/100-MWh battery. This may indicate that it would take larger battery system sizes before diminishing returns are seen in the southern grid.

As was seen in the Carson battery runs, the model places little value on increased energy storage capacity. Again, the 100-MW/400-MWh battery system yields approximately the same level of benefit as does the 100-MW/100-MWh system. The model values the ability of the battery to provide reserve, and does not find benefit in using it for time-of-day shifting. 


\subsection{New Generation Scenarios}

For NV Energy to own or procure energy storage services, it would likely need to obtain approval from the State of Nevada Public Utilities Commission (PUCN) to include the capital cost of the storage facility in its rate base. In order to obtain this approval, NV Energy would likely need to specify the need that the proposed resource addresses, perform an economic evaluation of the resource and alternatives (including not addressing the need), and evaluate the effect on ratepayers.

Requiring a storage project to be beneficial on its own is a high bar to meet. Whether a conventional generator could pay for itself in system cost savings is an open question. In order to assess the value of storage, it is therefore necessary to compare storage to another option capable of providing system peaking capacity.

Not taking into account ON Line capacity or intertie import capacity from neighboring grids, the study team found that generation capacity in the northern grid was inadequate to meet load in certain hours in 2020. It is therefore not unreasonable to assume that additional capacity in the north might be needed.

For this new capacity, we assume that a reciprocating engine plant might be the preferred option, since it would be a good alternative to storage in its ability to supply reserve and quickly ramp to compensate for changes in wind generation. We specified two plant capacities: $100 \mathrm{MW}$ and $300 \mathrm{MW}$. The 100-MW plant was assumed to be made up of 10 units of $10 \mathrm{MW}$ each, and the 300-MW plant was simply assumed to be three of the 100-MW plants located at the same site. The characteristics for these units were derived from the literature of a reciprocating engine manufacturer.

Table 3.9. New Generation Plant Scenario Results

\begin{tabular}{lcccc}
\hline $\begin{array}{c}\text { Scenario Description } \\
\text { (m USD) }\end{array}$ & $\begin{array}{c}\text { Annual } \\
\text { Generation } \\
\text { Cost }\end{array}$ & $\begin{array}{c}\text { Generator } \\
\text { Start and } \\
\text { Shutdown Cost }\end{array}$ & $\begin{array}{c}\text { Total } \\
\text { Generation } \\
\text { Cost }\end{array}$ & $\begin{array}{c}\text { Annual } \\
\text { Savings }\end{array}$ \\
\hline Reference & 990.8 & 25.6 & $1,016.3$ & - \\
Carson City NewGen 100 MW & 989.0 & 25.5 & $1,014.4$ & 1.9 \\
Carson City NewGen 300 MW & 986.8 & 24.0 & $1,010.8$ & 5.6 \\
\hline
\end{tabular}

As shown in Table 3.9, the 100-MW plant provided roughly 1.9 million USD in annual savings, and the 300-MW plant provided roughly 5.6 million USD in annual savings. At these levels of capacity, the returns for additional megawatts of capacity were roughly constant.

\subsection{Additional Sensitivity Analysis Scenarios}

Figure 3.1 compares the value of energy storage across different power capacities and energy storage capacities. These runs considered a storage system with $81 \%$ round-trip efficiency. The runs examine storage systems with one, four, and eight hours of storage at several different power ratings: $100 \mathrm{MW}$, $300 \mathrm{MW}, 500 \mathrm{MW}, 1000 \mathrm{MW}$, and $2500 \mathrm{MW}$. These are modeled as being located at the Robinson substation in northern Nevada. 


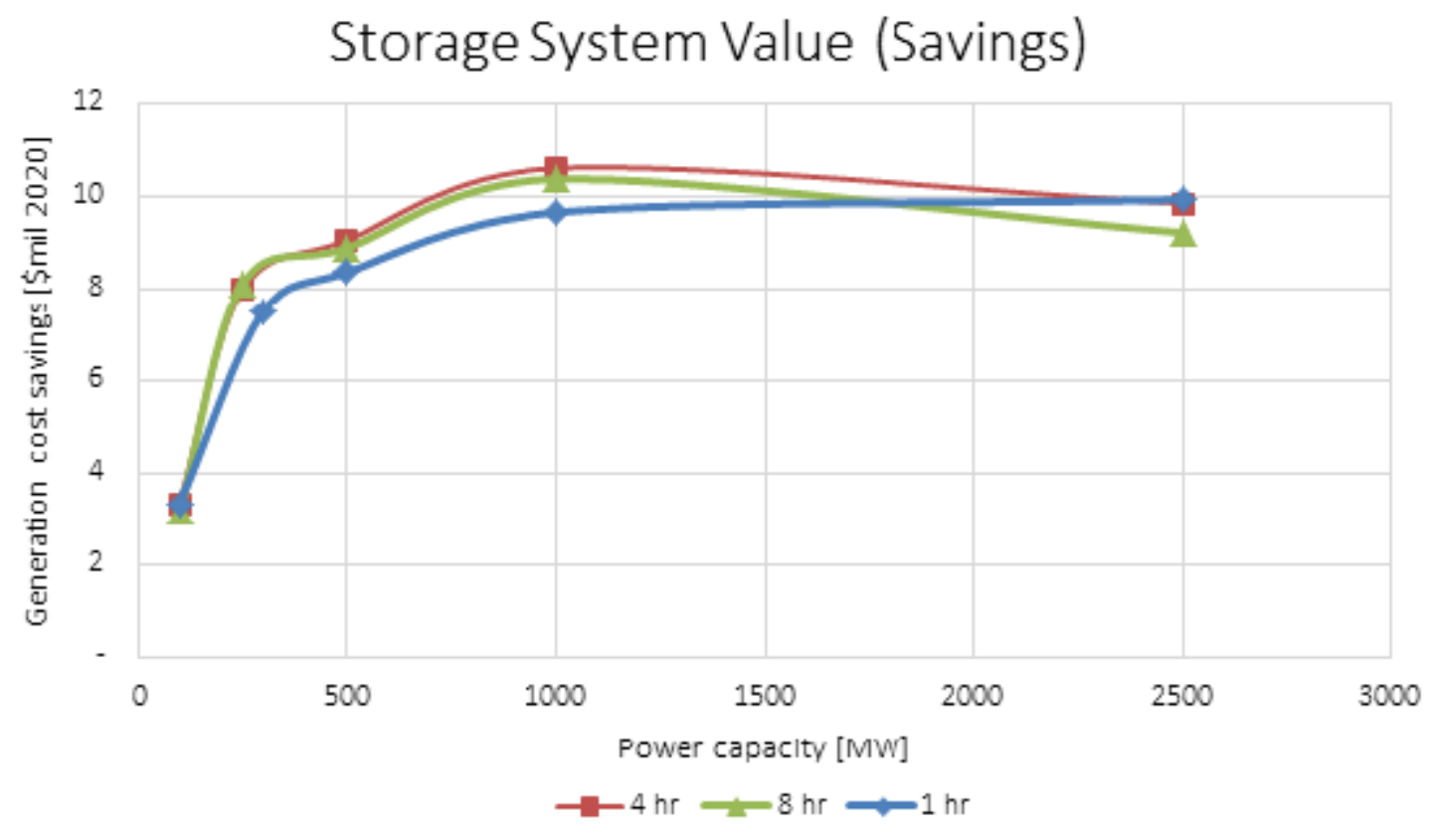

Figure 3.1. Additional Storage System Sensitivity Results

As storage power capacity increases from $100 \mathrm{MW}$ to $1000 \mathrm{MW}$, there are two characteristics apparent for energy storage in the Nevada power system. First, the difference in value between one hour, four hour and eight hour storage resources is small. The storage resources are primarily used to provide regulation, spinning and replacement reserves. The ability to perform time-of-day shifting, given the fuel price assumed and characteristics of the Nevada system in 2020, provides little additional value, and is therefore rarely used.

Second, there are decreasing returns to increased power capacity ratings with the value peaking at approximately $1 \mathrm{GW}$ of installed capacity at all hourly levels. Beyond around $300 \mathrm{MW}$ of installed capacity, the marginal benefits of additional storage decline.

These results are similar to those found in the main set of scenario runs, and thus help to build confidence in the findings. 


\subsection{Project Economic Evaluation}

Given the results as outlined in Section 3, would it make sense to invest in any of the scenario storage facilities from a cost-benefit basis? In other words, are the annual savings high enough to justify the initial project cost?

To examine this question, the project team started with the 2020 annual savings calculated for each scenario. We assumed that the project life for a battery storage facility is 15 years, and that the project life for a pumped storage hydro facility is 40 years. We further assumed that the annual savings for 2020 continues for the life of each project. In addition, we assumed that annual inflation is $2.5 \%$ for the project life, and that the discount rate is $8 \%$. No terminal value was assumed for these projects.

Table 4.1 shows the assumed capital cost, simple payback, and Net Present Value ("NPV”) for each project as calculated. The capital costs assumed here were $1,600 \mathrm{USD} / \mathrm{kW}$ for a pumped storage hydro facility, 2,400 USD/kW for a lithium ion battery with $4 \mathrm{kWh}$ of energy storage capacity for each $\mathrm{kW}$ of power capacity, and 1,100 USD/kW for a lithium ion battery with $1 \mathrm{kWh}$ of energy storage capacity for each $\mathrm{kW}$ of power capacity. The pumped storage hydro cost assumed is at the low end of the capital cost range, and does not take into account site-specific issues that could increase capital costs.

Table 4.1. Project Economic Evaluation

\begin{tabular}{lccccc}
\hline $\begin{array}{c}\text { Scenario Description (numbers in m USD } \\
\text { unless otherwise noted) }\end{array}$ & $\begin{array}{c}\text { Annual } \\
\text { Savings }\end{array}$ & $\begin{array}{c}\text { Capital Cost } \\
(\$ / \mathrm{kW})\end{array}$ & $\begin{array}{c}\text { Total } \\
\text { Capital } \\
\text { Cost }\end{array}$ & $\begin{array}{c}\text { Simple } \\
\text { Payback } \\
\text { (years) }\end{array}$ & NPV \\
\hline El Dorado PSH & 8.1 & 1,600 & 480 & 59 & $(340)$ \\
Robinson PSH & 7.2 & 1,600 & 480 & 67 & $(355)$ \\
El Dorado and Robinson & 9.8 & 1,600 & 960 & 98 & $(791)$ \\
Sunrise 100 MW/400 MWh & 5.1 & 2,400 & 240 & 47 & $(183)$ \\
Sunrise 100 MW/100 MWh & 4.9 & 1,100 & 110 & 22 & $(55)$ \\
Sunrise 50 MW/50 MWh & 2.3 & 1,100 & 55 & 24 & $(30)$ \\
Sunrise 25 MW/25 MWh & 1.2 & 1,100 & 27.5 & 22 & $(14)$ \\
Carson 100 MW/400 MWh & 3.4 & 2,400 & 240 & 70 & $(202)$ \\
Carson 100 MW/100 MWh & 3.6 & 1,100 & 110 & 30 & $(70)$ \\
Carson 50 MW/50 MWh & 2.1 & 1,100 & 55 & 26 & $(32)$ \\
Carson 25 MW/25 MWh & 1.5 & 1,100 & 27.5 & 19 & $(11)$ \\
Carson City NewGen 100 MW & 1.9 & 1,000 & 100 & 53 & $(67)$ \\
Carson City NewGen 300 MW & 5.6 & 1,000 & 300 & 54 & $(204)$ \\
\hline
\end{tabular}

Given the assumptions made in calculating project NPV, none of the scenario projects have a positive NPV. The project closest to having a positive NPV is the Carson 25-MW battery, with a negative 11m USD NPV.

These results point to a need to both decrease project capital costs, as well as find additional sources of value, in order for a project to be worthwhile from a cost-benefit perspective. If capital costs for the battery systems were to be reduced to $650 \mathrm{USD} / \mathrm{kW}$, then the Carson 25-MW battery would have roughly 
a zero NPV. This reduction in capital cost could potentially come from advances in Lithium Ion battery manufacturing, or it could come from using a different type of battery altogether, such as an advanced lead-acid battery. Since the battery is most needed to provide regulation reserve, as opposed to many deep discharge cycles, an advanced lead-acid battery may well be suited to the task, and may cost less than a Lithium Ion battery.

As for additional sources of value, the annual savings here are bulk grid savings. If, say, the Carson 25-MW battery were to not be a single storage facility, but multiple distributed facilities, then it may be possible to use the storage systems to provide additional value to the system. Potential distributed applications could include feeder voltage control for distributed solar photovoltaic ("PV") generation and substation capacity expansion deferral. If NV Energy would need to take some measures to regulate feeder voltage given distributed PV in any case, then the distributed storage system would become more economically attractive. ${ }^{9}$

For NV Energy to own or procure energy storage services, it would likely need to obtain approval from the State of Nevada Public Utilities Commission ("PUCN") to include the capital cost of the storage facility in its rate base. In order to obtain this approval, NV Energy would likely need to specify the need that the proposed resource addresses, perform an economic evaluation of the resource and alternatives (including not addressing the need), and evaluate of the effect on ratepayers.

Requiring a storage project to be beneficial on its own is a high bar to meet. Whether a conventional generator could pay for itself in system cost savings is an open question. In order to assess the value of storage, it is therefore necessary to compare storage to another option capable of providing system peaking capacity.

Assuming more capacity will be needed for the northern grid, we can compare the results of the new reciprocating engine generation plants with storage capable of time-of-day shifting. (The one-hour systems should not be included in the comparison, as they would not likely be considered capable of meeting load in peak hours).

A 300-MW pumped storage hydro ("PSH”) facility in the northern grid has an NPV of roughly negative 355 million US Dollars (or 355m USD), whereas a new 300-MW reciprocating engine plant at Carson has an NPV of roughly negative 200m USD. Similarly, a 100-MW/400-MWh battery at Carson has an NPV of roughly negative 200m USD, whereas a 100-MW reciprocating engine plant at Carson has an NPV of roughly negative 70m USD.

Therefore, given the assumptions used for the discount rate, project capital cost, and natural gas prices, and assuming the level of savings achieved in the study year are a good approximation of the savings that accrue each year in the future, it seems that a modern, efficient reciprocating engine power plant (similar to the Barrick power plant in northern Nevada) would be a more cost-effective investment than would a storage facility.

\footnotetext{
${ }^{9}$ At the same time, increasing the number of applications served requires that the applications be assigned priorities. If a battery system is providing voltage control as a top priority, it may not be able to provide as much regulating reserve as it would otherwise.
} 
Using a lower discount rate would increase all storage system valuations. Assuming either a longer battery system life or a battery system terminal value would increase valuations for battery system storage. 


\subsection{Confidence in Results}

The main concern of this study was to understand how grid-level storage might most benefit the Nevada system, and to quantify the level of savings that various scenario storage facilities might provide the system.

The study team is confident in the mechanism by which electricity storage adds value to the Nevada system, which is through the provision of reserve. The reference case does not require much in the way of peaking unit operation, so there is not much difference between on-peak and off-peak cost of producing power. Therefore, there seems to be limited value in storage providing time-of-day shifting. There is value, however, in relieving the marginal combined cycle plant from the provision of reserve. This allows the plant to be dispatched less, and more efficient combined cycle plants to be dispatched more. It also allows the marginal combined cycle plant to be dispatched at higher, more efficient levels when energy is needed.

A weakness of the study is that for the cost-benefit calculations, the level of savings in 2020 is assumed to remain constant into the future. In the case of pumped storage hydro and the reciprocating engine plant, 2020 savings are assumed constant for 40 years. In the case of battery storage, 2020 savings are assumed constant for 15 years. Changes in load, fuel prices, and generation fleet composition (including increased variable generation capacity) are likely to change the level of savings.

At the same time, if the model were run for, say, 30 years, then this would introduce new uncertainties. We would have to project plant retirements, as well as project the size and type of new plants being built. We would also need to project natural gas prices and changes in load for each year. The results of this 30-year run would be highly dependent on these assumptions, which are difficult to make with certainty. While doing such an integrated resource plan would allow storage to be valued under a variety of different system conditions, this was beyond the scope of the study.

The price of fuel is an important variable in determining the value of services provided by storage. Conventional generation in Nevada is primarily natural gas-fired. If natural gas prices were to increase from what was assumed in the study ( $\$ 5.70$ per million Btu), the level of savings provided by storage would likely be greater than those discussed in this report. Likewise, decreases in natural gas prices from levels assumed would likely cause the level of savings from storage to decrease.

The study team is fairly confident that the storage cost savings estimates in this study are robust to small changes in existing unit characteristics. However, since the scenario storage facilities mainly added value by providing regulating reserve, the valuations are sensitive to how regulating reserve is specified, and how much a megawatt of regulating reserve from a storage device counts towards fulfilling the regulating reserve requirement. A megawatt of regulating reserve from a fast- responding resource may be able to replace two to three megawatts of a slower-responding resource (Makarov, 2008). This effect was not taken into account in this study. If considered, a properly specified grid-level storage facility may have a positive NPV even at today’s storage system capital costs.

The study team did not evaluate the level of reserve needed for the Nevada BA in 2020, but instead used an estimate of what NV Energy is likely to specify. A lower level of required reserve would decrease the cost of operating the system, but may also decrease the amount of reserve from storage that would be useful. 
This study focuses on quantifying the benefits of storage at the bulk grid level for energy and reserve provision. At the bulk level, a storage facility could also be used to provide transmission capacity expansion deferral, reactive power supply, and black start service. If a storage project were to be realized as multiple distributed units, these units could provide substation capacity expansion deferral, feeder voltage control, and backup power. As the penetration of customer-installed PV increases, the benefit from feeder voltage control could become substantial. Distributed storage units could also collectively provide services to the bulk grid. ${ }^{10}$

The provision of multiple services depends on the characteristics of the specific storage resource and the priority of services specified. Further study would be needed to evaluate the economics and performance abilities of storage resources for such a deployment. For example, a distribution value analysis would require additional work to identify possible distribution needs and to estimate the value of serving those needs. The value of having storage provide services beyond reserve and time-of-day shifting at the bulk grid level was not assessed in this study, and was therefore not included in storage cost-benefit calculations.

\footnotetext{
${ }^{10}$ For a detailed discussion of the various benefits that electricity storage can provide, as well as estimates of the value of those benefits, please see Energy Storage for the Electricity Grid (Eyer and Corey, 2010) and Electric Energy Storage Technology Options (Rastler, 2010).
} 


\subsection{Conclusions}

The study team drew the following conclusions:

- All storage scenarios examined enabled the grid to be operated at lower cost

- Storage was found to add value mainly by providing regulating and spinning reserve

- In the reference case, the Higgins Combined Cycle plant is frequently operated at mini- mum level to provide reserve

- When storage is introduced, least-cost dispatch favors using it for the provision of regulating and spinning reserve, thus reducing the need to use Higgins for this function

- With storage providing reserve, Higgins is dispatched less frequently, and dispatched at a higher level when needed (mainly for energy)

- Dispatching Higgins less means that more efficient plants can be dispatched more

- If regulating reserve from storage is valued the same as that from slower ramp rate resources, it appears that

- a reciprocating engine generator could provide additional capacity at a lower cost than a pumped hydro storage plant or large storage capacity battery system

- not taking into account its capacity value, a 25-MW/25-MWh battery storage facility would need to cost $\$ 650 / \mathrm{kW}$ or less in order to produce a positive NPV

- However, if the fast, responsive regulating reserve provided by storage is considered to be more useful to the grid than that from slower ramp rate resources

- then a grid-level storage facility may have a positive NPV even at today's storage system capital costs (about $\$ 1100 / \mathrm{kW}$ for a Lithium Ion facility with one hour of storage)

Study model runs showed that scenario storage in the Nevada system mainly adds value by relieving the marginal combined cycle unit from providing spinning and regulating reserve. This means less generation from the marginal unit (since it is no longer operating at minimum load in order to provide reserve), more generation from the more efficient combined cycle units (in order to make up the generation shortfall), and more efficient generation from the marginal unit (as when it operates, it is operating at a higher level, and is thus more efficient).

In the model runs performed, the hypothetical storage units relieve the burden of providing spinning and regulating reserve from the Higgins Combined Cycle plant, which was the largest provider of both categories of these reserves in the reference run. Primarily, the Higgins plant was dispatched in the reference case not to provide energy, but to provide reserve. When relieved of reserve provision, the Higgins units are dispatched fewer hours, but at higher levels.

If additional peak production capacity is needed, it makes sense to compare the economics of a peaker plant with that of, say, a pumped storage hydro or a four-hour battery facility. Given the assumptions used for the discount rate, project capital cost, and natural gas prices, assuming the level of savings achieved in the study year are a good approximation of the savings that accrue each year in the future, and assuming that regulating reserve from storage is valued the same as that from a slower resource, it seems 
that a modern, efficient reciprocating engine power plant would be a more cost-effective investment than would a storage facility.

While storage facilities with one hour of storage capacity are unlikely to significantly count towards additional peak generation capacity, in the study model runs they were more cost-effective at reducing production cost than storage with a larger energy capacity. This is because they reduced production cost almost as much as the larger energy capacity devices, at a much lower installed cost. Even so, the 25MW/25-MWh battery at Carson, under the assumptions used in this study, still yields an NPV of negative $11 \mathrm{~m}$ USD. Reducing the capital cost of the battery storage system to $650 \mathrm{USD} / \mathrm{kW}$ would provide for a NPV of zero.

Since the scenario storage facilities mainly added value by providing regulating reserve, storage valuations are sensitive to how regulating reserve is specified, and how much a megawatt of regulating reserve from a storage device counts towards fulfilling the regulating reserve requirement. A megawatt of regulating reserve from a fast-responding resource may be able to replace two to three megawatts of a slower-responding resource (Makarov, 2008). This effect was not taken into account in this study. If considered, a properly specified grid-level storage facility may have a positive NPV in Nevada even at today’s storage system capital costs.

In this study, the ability of storage to provide energy and reserve at the bulk grid level was examined. At the bulk level, a storage facility could also be used to provide transmission capacity expansion deferral, reactive power supply, and black start service. If a storage project were to be realized as multiple distributed units, these units could provide substation capacity expansion deferral, feeder voltage control, and backup power. Distributed storage units could also collectively provide services to the bulk grid. The value of having storage provide services beyond reserve and time-of- day shifting at the bulk grid level was not assessed in this study, and was therefore not included in storage cost-benefit calculations. 


\subsection{Bibliography}

Eyer, Jim and Garth Corey. Energy Storage for the Electricity Grid: Benefits and Market Potential Assessment Guide, a Study for the Energy Storage Systems Program. Sandia National Laborato- ries, Document number SAND2010-0815, February 2010.

Lu S, PV Etingov, R Diao, J Ma, NA Samaan, YV Makarov, X Guo, RP Shlatz, L Frantzis, T McClive, G Karlson, D Acharya, A Ellis, J Stein, C Hansen, V Chadliev, M Smart, R Salgo, R Sorensen, B Allen, and B Idelchik, Large-Scale PV Inte- gration Study, Pacific Northwest National Laboratory, Document number PNNL-20677, July 2011. http://www.pnnl.gov/main/publications/external/technical reports/PNNL-20677.pdf, accessed June 14, 2013.

Makarov, Yuri V., S. Lu, J. Ma, and T. B. Nguyen. Assessing the Value of Regulation Resources Based on Their Time Response Characteristics. Pacific Northwest National Laboratory, Document number PNNL - 17632, June 2008.

NV Energy. NV Energy company website. https://www.nvenergy.com/company/index.cfm, accessed March 8, 2013.

NV Energy. NV Energy Portfolio Standard Annual Report, Compliance Year 2011, April 1, 2012. https://www.nvenergy.com/renewablesenvironment/renewables/images, accessed March 8, 2013.

Rastler, Dan. Electric Energy Storage Technology Options: A White Paper Primer on Applications, Costs, and Benefits. EPRI, Palo Alto, CA 2010. Document number 1020676.

TEPPC Assumptions Matrix for the 2020 TEPPC Dataset.

http://www.wecc.biz/library/StudyReport/Documents/Assumptions\%20Matrix\%20for\%20the\%202020\% 20TEPPC\%20Dataset.pdf, accessed June 13, 2013. 
Appendix A

Nevada BA Conventional Generation Assumed for 2020 


\section{Appendix A}

\section{Nevada BA Conventional Generation Assumed for 2020}

This section details the conventional generation units which were represented in the production cost model for the combined Nevada Balancing Authority for 2020. The fuel for these units is natural gas, unless otherwise stated (in the Unit Type column). Please see Table A.1 for the NV Energy- owned conventional generation units that are represented in the model for the southern Nevada system.

Table A.1. Southern Nevada NV Energy Conventional Generation

\begin{tabular}{lllc}
\hline Station Name & Unit (or Block) & Unit (or Block) Type & Nameplate Capacity \\
\hline \multirow{2}{*}{ Clark Complex } & Clark 4 & Gas Turbine & 60 \\
& Clark 9 CC & Combined Cycle & 250 \\
& Clark 10 CC & Combined Cycle & 250 \\
& Clark 11 to 22 & Gas Turbines & 680 \\
& Lenzie CC1 & Combined Cycle & 600 \\
& Lenzie CC2 & Combined Cycle & 600 \\
Chuck Lenzie Complex & Harry Allen 3 & Gas Turbine & 70 \\
& Harry Allen 4 & Gas Turbine & 70 \\
& Harry Allen CC & Combined Cycle & 525 \\
& Reid Gardner 1 & Steam Turbine (Coal) & 100 \\
& Reid Gardner 2 & Steam Turbine (Coal) & 100 \\
Reid Gardner Station & Reid Gardner 3 & Steam Turbine (Coal) & 100 \\
& Reid Gardner 4 & Steam Turbine (Coal) & 260 \\
\hline \multirow{2}{*}{ Silverhawk Station } & Silverhawk CC & Combined Cycle & 600 \\
\hline Higgins Station & Higgins CC & Combined Cycle & 525 \\
\hline
\end{tabular}

Table A.2 outlines the NV Energy-owned conventional generation units represented in the model for the northern Nevada system.

Table A.3 lists the conventional power plants in Nevada that are not owned by NV Energy, and represented in the model to be in operation by 2020. 
Table A.2. Northern Nevada NV Energy Conventional Generation

\begin{tabular}{lllc}
\hline Station Name & Unit (or Block) & Unit (or Block) Type & Nameplate Capacity (MW) \\
\hline \multirow{2}{*}{ Ft. Churchill } & Ft. Churchill 1 & Steam Turbine & 110 \\
& Ft. Churchill 2 & Steam Turbine & 110 \\
& Tracy 1 & Steam Turbine (Gas) & 50 \\
& Tracy 2 & Steam Turbine & 80 \\
& Tracy 3 & Steam Turbine & 110 \\
Tracy Complex & Tracy 4 and 5 & Combined Cycle & 110 \\
& Tracy Power Block & Combined Cycle & 575 \\
& Clark Mountain 3 & Gas Turbine & 70 \\
& Clark Mountain 4 & Gas Turbine & 70 \\
& Valmy 1 & Steam Turbine (Coal) & 250 \\
Valmy Complex & Valmy 2 & Steam Turbine (Coal) & 270 \\
\hline
\end{tabular}

Table A.3. Non-NV Energy Conventional Generation in Nevada

\begin{tabular}{llc}
\hline Unit (or Block) name & Unit (or Block) Type & Nameplate Capacity (MW) \\
\hline Las Vegas Cogen I & Combined Cycle & 50 \\
Las Vegas Cogen II & Combined Cycle & 240 \\
Apex (Mirant) & Combined Cycle & 550 \\
El Dorado (Merchant) & Combined Cycle & 530 \\
NV Cogen Associates 1 & Combined Cycle & 90 \\
NV Cogen Associates 2 & Combined Cycle & 90 \\
Saguaro & Combined Cycle & 105 \\
Sun Peak & Gas Turbine & 240 \\
TRIC & Gas Turbine & 240 \\
TS Power (Newmont) & Steam Turbine (Coal) & 200 \\
Barrick & Reciprocating Engine & 110 \\
Winnemucca & Gas Turbine & 20 \\
\hline
\end{tabular}




\section{Appendix B}

Nevada BA Renewable Generation Assumed for 2020 


\section{Appendix B}

\section{Nevada BA Renewable Generation Assumed for 2020}

In addition to the conventional units, renewable generation units expected to be in service for 2020 were represented in the production cost model. Table B.1 lists the geothermal plants that are expected to be in operation (and under contract to deliver power to NV Energy) in 2020.

Table B.1. Projected Nevada Geothermal Generation in 2020

\begin{tabular}{lc}
\hline Station Name & Nameplate Capacity (MW) \\
\hline Beowawe & 17.7 \\
Clayton Valley & 53.5 \\
Desert Peak 2 & 25 \\
Desert Peak 3 & 10 \\
Dixie Meadows & 51 \\
Faulkner & 49.5 \\
Galena 3 & 21.3 \\
Jersey Valley & 22.5 \\
McGuinness Hills & 51 \\
Richard Burdette & 26 \\
Salt Wells & 15.2 \\
San Emidio & 14 \\
Soda Lake & 23.1 \\
Steamboat IV & 62 \\
Stillwater & 47 \\
Tuscarora & 48 \\
\hline Note: Tuscarora was previously called the Hot Sulphur \\
Springs project. & \\
\hline
\end{tabular}

Table B.2. Projected Nevada Solar Generation in 2020

\begin{tabular}{llc}
\hline Station Type & Station Name & Nameplate Capacity (MW) \\
\hline \multirow{2}{*}{ Thermal } & Crescent Dunes & 110 \\
& Nevada Solar One & 75 \\
& ACE Searchlight & 17.5 \\
& Apex Mtn View & 40 \\
Photovoltaic & FRV Spectrum & 30 \\
& Nellis II & 12 \\
& Next Light Silver State & 50 \\
& Stillwater PV & 20 \\
\hline
\end{tabular}


Table B.3. Projected Nevada Wind Generation in 2020

\begin{tabular}{lc}
\hline \multicolumn{1}{c}{ Station Name } & Nameplate Capacity (MW) \\
\hline China Mountain & 200 \\
Spring Valley & 150 \\
Virginia Peak & 100 \\
\hline
\end{tabular}


Appendix C

Choice of Nodes for Battery Storage 



\section{Appendix C}

\section{Choice of Nodes for Battery Storage}

Our primary goal was to have one node in the southern system, and one node in the northern system. This is because the reference run showed that there were times that the ON Line linking the two systems was at capacity, and so we felt that the choice of which system to located the storage in could be important. Initially, our thinking was to choose the node by placing a 100MW/400MWh battery at several nodes in each system, and to identify the node in each system that yielded the highest annual generation cost savings.

Table C.1. Nodal Analysis of 100MW/400MWh Storage System

\begin{tabular}{clccc}
\hline Region & Node Name & $\begin{array}{c}\text { WECC Node } \\
\text { Number }\end{array}$ & $\begin{array}{c}\text { Annual Savings } \\
\text { (Current Runs) } \\
\text { USD) }\end{array}$ & $\begin{array}{c}\text { Annual Savings } \\
\text { (Original Runs) (m } \\
\text { USD) }\end{array}$ \\
\hline Southern & PAHRUMP & 18023 & 5.2 & 3.4 \\
& CLARK 6 & 18009 & 5.0 & 3.6 \\
& MEAD & 19011 & 5.0 & 2.8 \\
& SUNRISE & 18454 & 4.9 & 4.0 \\
\multirow{5}{*}{ Northern } & HAN CRTP & 64202 & 3.6 & 5.0 \\
& VAL RD N & 64125 & 3.5 & 5.4 \\
& PINSN TP & 64201 & 3.6 & 5.2 \\
& CARSON & 64026 & 3.6 & 5.5 \\
\hline
\end{tabular}

Initially, the Sunrise node in the south and the Carson node in the north provided the greatest savings in their respective regions. These two nodes were chosen to test battery systems of various sizes, as described in Table 2.1. However, as can be seen in Table C.1, after modifying some of the generation unit characteristics, the testing by node yielded somewhat different results. Carson is still one of the top performing nodes in the northern system, but it is no longer the single best node in the north. And Sunrise went from the top performing node to the worst performing node among those tested for the southern system.

Also of note is that initially, the northern nodes provided the greatest savings, whereas the modified system shows the southern nodes as providing the greatest savings. This indicates that there are times at which the ON Line is at capacity, and that the model is fairly sensitive to unit characteristic changes that impact ON Line congestion.

The study team did not feel it warranted to select Pahrump rather than Sunrise for the nodal battery testing for the southern system. This is because the system is likely to change between now and 2020 in ways not reflected in this model, such as additional generation in the north. We did not feel confident that we could identify the best node with certainty, given the sensitivity of the model; therefore, we felt that essentially selecting a random node in the south and a random node in the north would be sufficient for the purposes of this study. If NV Energy is interested in proceeding with specifying a battery storage 
system, we would recommend a more detailed investigation into which node (and even whether the node should be in the northern or southern system) would likely yield the most benefits. 



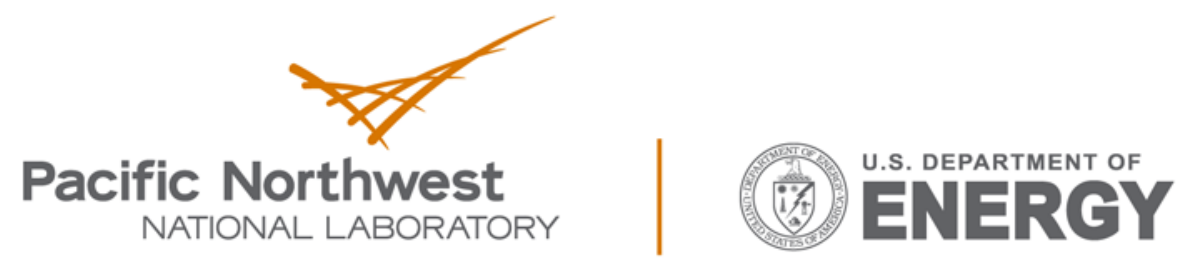

Proudly Operated by Battelle Since 1965

902 Battelle Boulevard

P.O. Box 999

Richland, WA 99352

1-888-375-PNNL (7665)

www.pnnl.gov 